EXTENDED REPORT

\title{
Tibial plateau size is related to grade of joint space narrowing and osteophytes in healthy women and in women with osteoarthritis
}

\author{
A E Wluka, Y Wang, S R Davis, F M Cicuttini
}

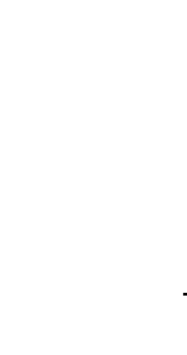

See end of article for

authors' affiliations

Ann Rheum Dis 2005;64:1033-1037. doi: 10.1136/ard.2004.029082

....................

Correspondence to:

Associate

Professor Flavia Cicuttini,

Department of

Epidemiology and

Preventive Medicine,

Monash University-Central

and Eastern Clinical

School, Alfred Hospital,

Commercial Road,

Melbourne, VIC 3004 ,

Australia; flavia.cicuttini@

med.monash.edu.au

Accepted

27 November 2004

Published Online First

15 December 2004

\begin{abstract}
Objective: To determine the relation of bone size to radiographic severity in knee osteoarthritis.
Methods: 149 women (81 healthy and 68 with knee osteoarthritis) underwent knee radiography and magnetic resonance imaging on their symptomatic or dominant knee. Tibial plateau bone area was measured at baseline and at follow up.

Results: Women with osteoarthritis had larger medial and lateral tibial plateau bone area (mean (SD): $1850(240) \mathrm{mm}^{2}$ and $1279(220) \mathrm{mm}^{2}$, respectively) than healthy women $\left(1670(200) \mathrm{mm}^{2}\right.$ and 1050 (130) $\left.\mathrm{mm}^{2}\right)(\mathrm{p}<0.001$ for both differences). For each increase in grade of osteophyte, an increase in bone area was seen of $146 \mathrm{~mm}^{2}$ in the medial compartment and $102 \mathrm{~mm}^{2}$ in the lateral compartment. Similarly, for each increase in grade of joint space narrowing, tibial plateau bone area increased by $160 \mathrm{~mm}^{2}$ in the medial compartment and $131 \mathrm{~mm}^{2}$ in the lateral compartment (significance of regression coefficients all $p<0.001$ ). These relations persisted after adjusting for potential confounders, with the exception of the association between grade of medial osteophytes and medial plateau area.

Conclusions: With increasing severity of radiographic knee osteoarthritis, tibial plateau size increases. Whether this bone increase plays a role in the pathogenesis of osteoarthritis remains to be determined.
\end{abstract}

.....................

$\mathrm{O}$ steoarthritis is a common chronic disease, resulting in degeneration of articular cartilage and changes in subchondral bone (sclerosis and cyst formation) and periarticular bone (osteophytes). Whether the primary defect of osteoarthritis occurs in subchondral bone or in articular cartilage is unclear. ${ }^{1}$ We have shown that people with knee osteoarthritis have less knee cartilage than normal individuals and that tibial bone size is an independent predictor of the amount of knee cartilage. ${ }^{2-5}$ A recent study showed that those with grade I osteophytes had increased medial and lateral tibial plateau bone area compared with those with no evidence of osteoarthritis. ${ }^{6}$ Those with a higher grade of osteophytes were not included in that study. No relation between tibial plateau area and joint space narrowing was observed. If there is a concomitant reduction in knee cartilage volume with an increase in bone size with increasing severity of osteoarthritis, this is likely to have a major impact on knee cartilage thickness and potentially on load distribution and the pathogenesis of knee osteoarthritis.

We undertook a cross sectional study to explore the hypothesis that there is a relation between tibial plateau area and the features of radiographic osteoarthritis in that joint compartment, across the spectrum of knee osteoarthritis from the normal joint to grade III radiographic osteophytes and joint space narrowing. We restricted the study to women in order to deal with the confounding effect of sex.

\section{METHODS}

We studied female subjects aged over 40 years who had been involved in investigations in which a radiograph and magnetic resonance imaging (MRI) of the knee had been carried out in our unit. Subjects had been recruited through the Jean Hailes Centre (a women's health clinic), private consulting clinics (rheumatologists, orthopaedic surgeons, general practitioners), and through advertising in the local media.
Subjects included those with established knee osteoarthritis and healthy non-osteoarthritic subjects. Those without osteoarthritis had initially been recruited for a study of healthy aging and had no significant pain at baseline. We have previously described this group. ${ }^{2}$ Subjects with osteoarthritis had pain attributable to knee osteoarthritis and radiographic evidence of osteoarthritis (osteophytes in the knee), ${ }^{4}$ so they met the American Academy of Rheumatology (ACR) clinical and radiographic criteria for knee osteoarthritis. ${ }^{7}$

The study was approved by the ethics committee of the Alfred and Caulfield Hospitals in Melbourne, Australia. All subjects provided informed consent.

The exclusion criteria were: inflammatory arthritis, previous knee joint replacement, malignancy, fracture in the last 10 years, and contraindication to MRI (for example, pacemaker, cerebral aneurysm clip, cochlear implant, presence of shrapnel in strategic locations, metal in the eye, and claustrophobia), inability to walk 50 feet without the use of assistive devices, hemiparesis of either lower limb, and planned total knee replacement.

All subjects completed a questionnaire to obtain information on demographic data, current physical activity, ${ }^{8}$ and smoking history (ever versus never smoked). Weight was measured to the nearest $0.1 \mathrm{~kg}$ (shoes and bulky clothing removed) using a single pair of electronic scales. Height was measured to the nearest $0.1 \mathrm{~cm}$ (shoes removed) using a stadiometer. Body mass index (BMI) $\left(\mathrm{kg} / \mathrm{m}^{2}\right)$ was calculated. General health status was assessed by the short form 36 item health survey (SF-36). ${ }^{9}$ Knee pain and function were assessed using the knee specific WOMAC index (Western Ontario and McMaster Universities osteoarthritis index). ${ }^{10}$

At study entry, each subject had a weight bearing anteroposterior tibiofemoral radiograph taken in full extension. In asymptomatic healthy subjects, the dominant knee was imaged. The dominant knee was defined as the lower 

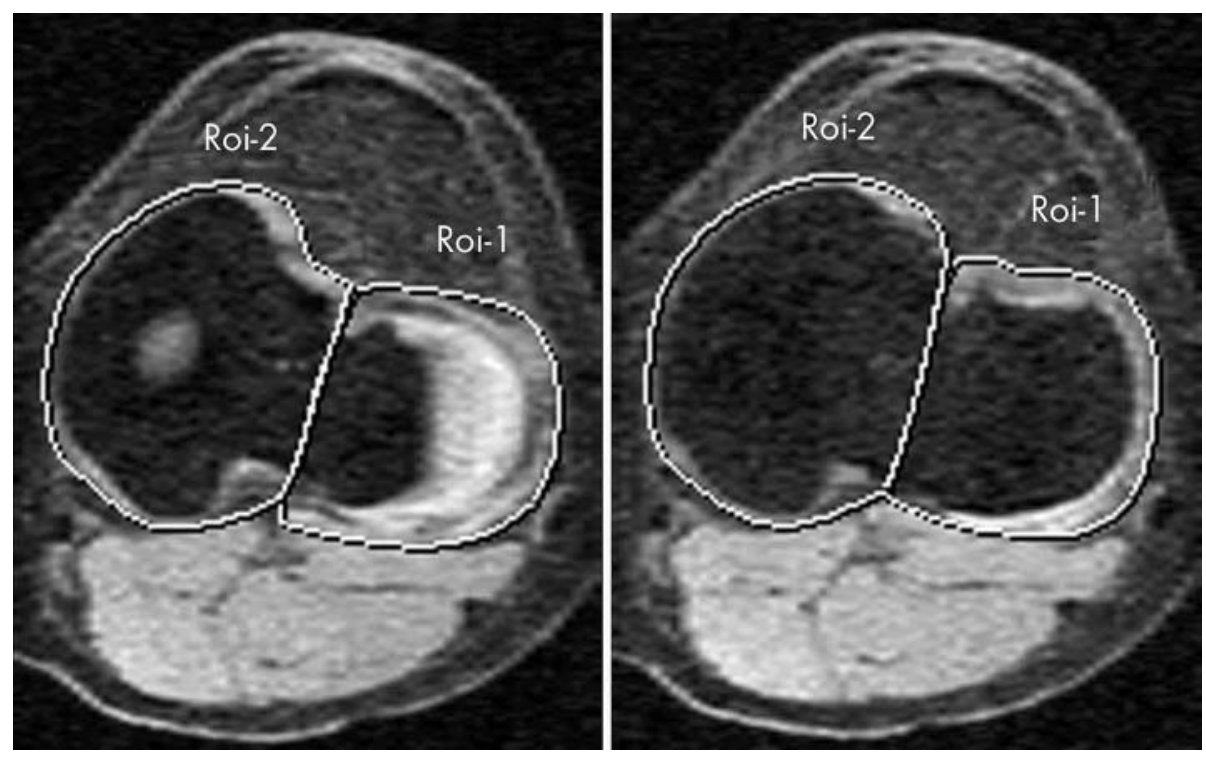

Figure 1 Axial Tl weighted fat saturated three dimensional magnetic resonance image showing the method of measuring the tibial plateau bone area. The area of medial (Roi-2) and lateral (Roi-1) tibial plateau bone is measured manually on the image on the left, which shows both tibial cartilage and subchondral bone and the next image distal to the joint, shown on the right. An average of the two areas is used as an estimate of the tibial plateau bone area.

limb from which she stepped off when walking. In subjects with osteoarthritis, the symptomatic knee was imaged, but where both were symptomatic, both knees were imaged, and the knee with less severe radiographic changes was used as the study joint. These radiographs were independently scored in duplicate by a trained observer, who used a published atlas to classify disease in the tibiofemoral joint. ${ }^{11}$ The radiological features of tibiofemoral osteoarthritis were graded in each compartment on a four point scale (0-III) for individual features of femoral osteophytes, tibial osteophytes, and joint space narrowing, where 0 designates no evidence of osteoarthritis, and III designates severe radiographic disease. ${ }^{11}$ In the case of disagreement between readings, the films were reviewed with an independent observer. The intraobserver reproducibility as measured by the $\kappa$ statistic was 0.92 for tibial osteophytes and 0.90 for femoral osteophytes, and 0.82 for medial and 0.80 for lateral joint space narrowing.

Each subject had MRI of the study knee. Knees were imaged in the sagittal plane on the same $1.5 \mathrm{~T}$ whole body magnetic resonance unit (Signa Advantage HiSpeed GE Medical Systems, Milwaukee, Wisconsin, USA) using a commercial receive-only extremity coil with a previously described sequence. ${ }^{5}$ One trained reader did the measurements in duplicate. Medial and lateral tibial plateau bone areas were determined by means of image processing on an independent work station using the software program Osiris, by creating an isotropic volume from the input images which were reformatted in the axial plane, after which areas were directly measured from these axial images as previously described. ${ }^{4}$ To measure the tibial plateau bone area, we selected the first image which showed both tibial cartilage and subchondral bone. The area of medial and lateral tibial plateau bone was measured on this image and the next distal image manually (fig 1). An average of the two areas was used as an estimate of the tibial plateau bone area. The coefficient of variation for the medial and lateral tibial plateau areas were $2.3 \%$ and $2.4 \%$, respectively, for the repeated image analysis. ${ }^{4}$

\section{Statistics}

Descriptive statistics for characteristics of the subjects were tabulated. Independent $t$ tests were used for comparison of means. Fisher's exact test was used to compare categorical characteristics between the groups. Tibial bone area in healthy and osteoarthritis women was compared using independent $t$ tests. The effect of potential confounding

Table 1 Clinical characteristics of subjects

\begin{tabular}{lllr}
\hline Variable & Normal $(\mathbf{n = 8 1 )}$ & $\begin{array}{l}\text { Osteoarthritis } \\
(\mathbf{n = 6 8 )}\end{array}$ & p Value \\
\hline Age (years) & $57(5.8)$ & $63(10.3)$ & $<0.001$ \\
Height (m) & $1.63(0.07)$ & $1.62(0.06)$ & 0.12 \\
Weight (kg) & $70.2(13.8)$ & $78.3(15.4)$ & 0.001 \\
BMl, $\mathrm{kg} / \mathrm{m}^{2}$ & $26.3(5.1)$ & $30.0(5.8)$ & $<0.001$ \\
Pain (WOMAC) & $1.7(2.8)$ & $83.3(46.1)$ & $<0.001$ \\
Physical function (SF-36) & $5.2(6.2)$ & $37.2(10.0)$ & $<0.001$ \\
Mental health function (SF-36) & $49.1(9.0)$ & $52.9(9.8)$ & 0.02 \\
Physical activity level & $7.2(1.7)$ & $5.8(1.8)$ & $<0.001$ \\
Kellgren Lawrence $\geqslant 2$ (n (\%)) & $1(1 \%)$ & $17(26 \%)$ & $<0.001^{*}$ \\
\hline
\end{tabular}

Values are mean (SD) unless stated.

*Fisher's exact test.

BMI, body mass index; SF-36, short form 36 item general health questionnaire; WOMAC, Western Ontario and McMaster Universities osteoarthritis index. 
Table 2 Tibial plateau area in normal subjects compared to those with osteoarthritis

\begin{tabular}{|c|c|c|c|c|c|c|}
\hline & \multicolumn{3}{|l|}{ Crude analysis* } & \multicolumn{3}{|l|}{ Adjusted resultst } \\
\hline & Normal $(n=81)$ & Osteoarthritis ( $n=68$ ) & $\mathrm{p}$ Value & Normal $(n=81)$ & Osteoarthritis ( $n=68$ ) & p Value \\
\hline $\begin{array}{l}\text { Medial tibial area }\left(\mathrm{mm}^{2}\right) \\
\text { Lateral tibial area }\left(\mathrm{mm}^{2}\right)\end{array}$ & $\begin{array}{l}1670(200) \\
1050(130)\end{array}$ & $\begin{array}{l}1850(240) \\
1270(220)\end{array}$ & $\begin{array}{l}<0.001 \\
<0.001\end{array}$ & $\begin{array}{l}1660(30) \\
1080(30)\end{array}$ & $\begin{array}{l}1860(40) \\
1230(30)\end{array}$ & $\begin{array}{l}0.001 \\
0.003\end{array}$ \\
\hline
\end{tabular}

variables on the relation between bone area and radiographic osteoarthritis was explored by calculating estimated marginal means, using analysis of variance methods. Regression techniques were used to examine the relation between tibial plateau area and maximum grade of osteophyte and joint space narrowing in the medial and lateral tibiofemoral compartment. The effect of potential confounders was examined using logistic regression, with estimated marginal means calculated for the different radiographic grades. A probability ( $p$ ) value of $<0.05$ (two tailed) was regarded as significant. All analyses were carried out using the SPSS statistical package (version 11.0.0, SPSS Inc, Cary, North Carolina, USA).

\section{RESULTS}

Complete data were available for 81 healthy women and 68 women with osteoarthritis (table 1). Compared with the healthy women, those with osteoarthritis were older $(p<0.001)$, heavier $(p=0.001)$, had higher BMI $(p<0.001)$, experienced more pain $(\mathrm{p}<0.001)$, and had a lower level of physical function $(\mathrm{p}<0.001)$, a higher level of mental function $(p=0.02)$, and a lower level of physical activity $(\mathrm{p}<0.001)$.

Women with osteoarthritis had larger medial and lateral tibial plateau bone area (mean (SD): 1850 (240) $\mathrm{mm}^{2}$ and $1279(220) \mathrm{mm}^{2}$, respectively) than healthy women (1670 (200) $\mathrm{mm}^{2}$ and $\left.1050 \quad(130) \mathrm{mm}^{2}\right) \quad(\mathrm{p}<0.001$ for both differences; table 2 ). These results remained significant after accounting for potential confounding variables, including age, BMI, pain, and physical activity level (table 2 ).

In the initial analyses, in which the effect of covariates was not considered, a positive relation was observed between tibial plateau bone area and grade of osteophytes and joint space narrowing in each compartment (all p<0.001) (table 3 ). There was an increase in medial and lateral tibial plateau area of $146 \mathrm{~mm}^{2}$ and $102 \mathrm{~mm}^{2}$ for every increase in grade of osteophyte in the respective compartment, and of $160 \mathrm{~mm}^{2}$ and $131 \mathrm{~mm}^{2}$ for every increase in grade of joint space narrowing in the respective compartment. In multivariate analyses after adjusting for the potential confounders including age, height, weight, and grade of osteophytes/joint space narrowing, a higher grade of medial joint space narrowing was associated with an increased medial tibial plateau bone area $(\mathrm{p}<0.001)$. A higher grade of lateral osteophytes $(p=0.002)$ and joint space narrowing $(p=0.04)$ was associated with an increased lateral tibial plateau bone area. The association between grade of medial osteophytes and medial plateau area was not significant after accounting for covariates $(p=0.70)$. For each increase in grade of tibial or femoral osteophyte or grade of joint space narrowing there was an increase in the respective tibial plateau bone area (table 4).

\section{DISCUSSION}

We have shown that women with established knee osteoarthritis have larger tibial plateau areas than healthy women. These differences were not attributable to the baseline differences between the groups. We also found that tibial plateau bone area was related to the radiographic severity of osteoarthritis; tibial plateau bone area increased with increased grade of joint space narrowing in both medial and lateral compartments, while only lateral tibial plateau bone area increased with increased grade of osteophyte.

Bone size has been shown to increase with age and also with osteoarthritis. ${ }^{12}{ }^{13}$ Two previous studies have compared femoral neck size in subjects with osteoarthritis to normal subjects. Although a more recent MRI study found femoral neck area to be larger in men with hip osteoarthritis than in healthy controls matched for age and sex, ${ }^{14}$ an earlier smaller anatomical specimen study of 28 subjects with osteoarthritis and 16 controls found no difference, possibly owing to lack of power. ${ }^{15}$

Bone size, both adjacent to and distant to affected joints, has been shown to correlate with the severity of osteoarthritis. A recent study which examined the relation between tibial plateau area and early changes of radiographic knee osteoarthritis found a positive association between grade I osteophytosis and tibial plateau area. ${ }^{6}$ However, this study found no relation between tibial plateau area and joint space narrowing, perhaps because only healthy subjects with a

Table 3 The relation between tibial plateau area and individual radiographic characteristics of osteoarthritis

\begin{tabular}{|c|c|c|c|c|}
\hline & $\begin{array}{l}\text { Crude regression coefficient* } \\
(95 \% \mathrm{Cl})\end{array}$ & p Value & $\begin{array}{l}\text { Adjusted regression coefficientt } \\
(95 \% \mathrm{CI})\end{array}$ & p Value \\
\hline \multicolumn{5}{|l|}{ Medial tibial plateau area } \\
\hline Grade of osteophyte & $146(81$ to 212$)$ & $<0.001$ & $18(-41$ to 78$) \neq$ & 0.70 \\
\hline Joint space narrowing & 160 (120 to 201$)$ & $<0.001$ & $145(103$ to 186$) \S$ & $<0.001$ \\
\hline \multicolumn{5}{|l|}{ Lateral tibial plateau area } \\
\hline Grade of osteophyte & 102 (72 to 132 ) & $<0.001$ & $58(22$ to 95$) \ddagger$ & 0.002 \\
\hline Joint space narrowing & 131 (85 to 177 ) & $<0.001$ & $57(2$ to 113$) \S$ & 0.04 \\
\hline \multicolumn{5}{|c|}{$\begin{array}{l}\text { *Change in tibial plateau area for each change in grade of osteophyte or joint space narrowing }\left(\mathrm{mm}^{2}\right) \text {. } \\
\text { †Change in tibial plateau area for each change in grade of osteophyte or joint space narrowing, after accounting for potential covariates. } \\
\text { †Adjusted for age, height, weight, and grade of joint space narrowing. } \\
\text { §Adjusted for age, height, weight, and grade of osteophyte. } \\
\mathrm{Cl} \text {, confidence interval. }\end{array}$} \\
\hline
\end{tabular}


Table 4 The relation between tibial plateau area and individual radiographic characteristics of osteoarthritis

\begin{tabular}{|c|c|c|c|c|c|c|c|c|c|}
\hline & & \multicolumn{4}{|c|}{ Medial tibial plateau area } & \multicolumn{4}{|c|}{ Lateral tibial plateau area } \\
\hline & & Crude* & $\mathrm{p}$ Value & Adjustedt & p Value & Crude* $^{*}$ & $\mathrm{p}$ Value & Adjustedt & p Value \\
\hline $\begin{array}{l}\text { Femoral osteophyte } \\
\text { grade }\end{array}$ & $\begin{array}{l}0 \\
\text { I } \\
\text { II } \\
\text { III }\end{array}$ & $\begin{array}{l}1730(220) \\
1810(360) \\
2090(330) \\
-\ddagger\end{array}$ & 0.002 & $\begin{array}{l}1740(20) \\
1750(90) \\
2060(100) \\
-\ddagger\end{array}$ & 0.01 & $\begin{array}{l}1120(190) \\
1390(160) \\
1350(270) \\
1530(70)\end{array}$ & $<0.001$ & $\begin{array}{l}1130(20) \\
1300(70) \\
1250(70) \\
1390(130)\end{array}$ & 0.03 \\
\hline $\begin{array}{l}\text { Tibial osteophyte } \\
\text { grade }\end{array}$ & $\begin{array}{l}0 \\
\text { I } \\
\text { II } \\
\text { III }\end{array}$ & $\begin{array}{l}1730(220) \\
1960(360) \\
2050(140) \\
-\ddagger\end{array}$ & 0.008 & $\begin{array}{l}1730(20) \\
1920(90) \\
2010(160) \\
-\ddagger\end{array}$ & 0.03 & $\begin{array}{l}1120(170) \\
1310(260) \\
1740(380) \\
1550(40)\end{array}$ & $<0.001$ & $\begin{array}{l}1130(10) \\
1230(60) \\
1670(100) \\
1410(120)\end{array}$ & $<0.001$ \\
\hline $\begin{array}{l}\text { Joint space } \\
\text { narrowing }\end{array}$ & $\begin{array}{l}0 \\
1 \\
\text { II } \\
\text { III }\end{array}$ & $\begin{array}{l}1700(190) \\
1750(180) \\
2060(220) \\
2220(260)\end{array}$ & $<0.001$ & $\begin{array}{l}1700(20) \\
1750(50) \\
2040(90) \\
2190(70)\end{array}$ & $<0.001$ & $\begin{array}{l}1110(170) \\
1220(220) \\
1440(340) \\
1430(80)\end{array}$ & $<0.001$ & $\begin{array}{l}1120(20) \\
1190(40) \\
1340(70) \\
1350(110)\end{array}$ & 0.005 \\
\hline
\end{tabular}

*Mean (SD).

†Estimated marginal mean (SE), results adjusted for age, body mass index, pain, and exercise level.

†No result in group.

limited spectrum of disease were examined, with no more than grade I osteophytosis or joint space narrowing. Another study which compared femoral neck area in men with unilateral or bilateral hip osteoarthritis found that femoral neck size was greater in the hip with the higher osteoarthritis grade. ${ }^{14}$ However, as a composite score was used to grade osteoarthritis, the investigators were unable to comment on the relation between bone size and the individual radiographic characteristics of osteoarthritis. Upper limb indices of bone area have been linked to lower extremity osteoarthritis. For instance, radial width was found to be associated with the severity of knee osteoarthritis in a large study in 430 men but not in women, suggesting osteoarthritis may have systemic manifestations or aetiology. ${ }^{16}$ Indeed, in support of this hypothesis, the biochemical composition of bone in the iliac crest in women with hand osteoarthritis differed from that in women without hand osteoarthritis..$^{17}$

Some aspects of the current study need consideration. In order to deal with the confounding effect of sex, we only examined women. Whether these results are generalisable to men is to be determined. Bone area is the only marker of bone size we used. However, we have shown this method to be reproducible, and similar to the methods used by other investigators. $^{14}$ In this study we did not examine other measures of bone quantity such as density which may also be important. There were significant differences between the healthy women and those with osteoarthritis, including age, weight, BMI, pain, physical activity level, and so on. However, these factors have been accounted for in the analysis.

The increased tibial plateau area we observed in osteoarthritis may occur as a compensatory response to biomechanical factors, or may be the primary abnormality. With increasing grade of osteoarthritis the tibial bone area increased in size while the amount of knee cartilage decreased. ${ }^{3}$ This results in less articular cartilage, spread over a larger area, which may result in abnormal forces through the joint. This may further enhance cartilage loss in osteoarthritis.

Our study shows that in women, tibial plateau area may be related to the severity of radiographic knee osteoarthritis. It provides additional evidence that subchondral bone may be worthy of further investigation to identify factors influencing the progression of osteoarthritis.

\section{ACKNOWLEDGEMENTS}

We would like to acknowledge Judy Hankin, Vicki White, and Judy Snaddon for subject recruitment and duplicate measurements. We acknowledge the Shepherd Foundation and NHMRC for support. Special thanks to the participants who made this study possible.

\section{Authors' affiliations}

A E Wluka, Y Wang, F M Cicuttini, Department of Epidemiology and Preventive Medicine, Monash University Medical School, Alfred Hospital, Prahran, Victoria, Australia

Y Wang, Graduate School of Integrative Medicine, Swinburne University of Technology, Hawthorn, Victoria, Australia

S R Davis, Jean Hailes Foundation, Clayton, Victoria, Australia

\section{REFERENCES}

1 Dieppe P. Subchondral bone should be the main target for the treatment of pain and disease progression in osteoarthritis. Osteoarthritis Cartilage 1999;7:325-6.

2 Wluka AE, Davis SR, Bailey M, Stuckey SL, Cicuttini FM. Users of oestrogen replacement therapy have more knee cartilage than non-users. Ann Rheum Dis 2001;60:332-6.

3 Cicuttini FM, Wluka AE, Wolfe R, Forbes A. Comparison of tibial cartilage volume and radiologic grade of the tibiofemoral joint. Arthritis Rheum 2003;48:682-8.

4 Wluka AE, Stuckey S, Snaddon J, Cicuttini FM. The determinants of change in tibial cartilage volume in osteoarthritic knees. Arthritis Rheum 2002:46:2065-72.

5 Cicuttini F, Forbes A, Morris K, Darling S, Bailey M, Stuckey S. Gender differences in knee cartilage volume as measured by magnetic resonance imaging. Osteoarthritis Cartilage 1999;7:265-71.

6 Jones G, Ding C, Scott F, Glisson M, Cicuttini FM. Early radiographic osteoarthritis is associated with substantial changes in cartilage volume and tibial bone surface area in both males and females. Osteoarthritis Cartilage 2004; 12:169-74.

7 Altman R, Asch E, Bloch D, Bole G, Borenstein D, Brandt K, et al. Development of criteria for the classification and reporting of osteoarthritis. Classification of osteoarthritis of the knee. Diagnostic and Therapeutic Criteria Committee of the American Rheumatism Association. Arthritis Rheum 1986;29:1039-49.

8 Spector TD, Harris PA, Hart DJ, Cicuttini FM, Nandra D, Etherington J, et al. Risk of osteoarthritis associated with long-term weight-bearing sports: a radiologic survey of the hips and knees in female ex-athletes and population controls. Arthritis Rheum 1996;39:988-95.

9 Ware JEJ, Snow KK, Kosinski M, Gandek B. SF-36 health survey: manual and interpretation guide. Boston: The Health Institute, New England Medical Center, 1993.

10 Bellamy N, Buchannan WW, Goldsmith CH, Campbell J, Stitt LW. Validation study of WOMAC: a health status instrument for measuring clinically important patient relevant outcomes to antirheumatic drug therapy in patients with osteoarthritis of the hip or knee. J Rheumatol 1988;15:1833-40.

11 Altman RD, Hochberg M, Murphy WA, Wolfe F, Lequesne M. Atlas of individual radiographic features in osteoarthritis. Osteoarthritis Cartilage 1995;3(suppl A):3-70.

12 Smith RW, Walker RR. Femoral expansion in ageing women: implications for osteoporosis and fractures. Science 1964;145:156-7.

13 Haapasalo $H$, Kontulainen S, Sievanen H, Kannus $P$, Jarvinen M, Vuori I. Exercise-induced bone gain is due to enlargement in bone size without a change in volumetric bone density: a peripheral quantitative computed tomography study of the upper arms of male tennis players. Bone 2000;27:351-7. 
14 Arokoski JP, Arokoski MH, Jurvelin JS, Helminen HJ, Niemitukia LH, Kroger H. Increased bone mineral content and bone size in the femoral neck of men with hip osteoarthritis. Ann Rheum Dis 2002;61:145-50.

15 Moore RJ, Fazzalari NL, Manthey BA, Vernon-Roberts B. The relationship between head-neck-shaft angle, calcar width, articular cartilage thickness and bone volume in arthrosis of the hip. Br J Rheumatol 1994;33:432-6.

16 Hochberg MC, Lethbridge-Cejku M, Scott WW, Reichle R, Plato CC, Tobin JD. Upper extremity bone mass and osteoarthritis of the knees: data from the Baltimore Longitudinal Study of Aging. J Bone Miner Res 1995;10:432-8.
17 Gevers G, Dequeker J. Collagen and non-collagenous protein content (osteocalcin, sialoprotein, proteo-glycan) in the iliac crest bone and serum osteocalcin in women with and without hand osteoarthritis. Coll Relat Res 1987:1987:435-42.

18 Dequeker J, Mohan S, Finkelman RD, Aerssens J, Baylink DJ. Generalized osteoarthritis associated with increased insulin-like growth factor types I and II and transforming growth factor beta in cortical bone from the iliac crest. Possible mechanism of increased bone density and protection against osteoporosis. Arthritis Rheum 1993;36:1702-8.

\section{Clinical Evidence-Call for contributors}

Clinical Evidence is a regularly updated evidence-based journal available worldwide both as a paper version and on the internet. Clinical Evidence needs to recruit a number of new contributors. Contributors are healthcare professionals or epidemiologists with experience in evidence-based medicine and the ability to write in a concise and structured way.

Areas for which we are currently seeking authors:

- Child health: nocturnal enuresis

- Eye disorders: bacterial conjunctivitis

- Male health: prostate cancer (metastatic)

- Women's health: pre-menstrual syndrome; pyelonephritis in non-pregnant women

However, we are always looking for others, so do not let this list discourage you.

Being a contributor involves:

- Selecting from a validated, screened search (performed by in-house Information Specialists) epidemiologically sound studies for inclusion.

- Documenting your decisions about which studies to include on an inclusion and exclusion form, which we keep on file.

- Writing the text to a highly structured template (about 1500-3000 words), using evidence from the final studies chosen, within 8-10 weeks of receiving the literature search.

- Working with Clinical Evidence editors to ensure that the final text meets epidemiological and style standards.

- Updating the text every six months using any new, sound evidence that becomes available. The Clinical Evidence in-house team will conduct the searches for contributors; your task is simply to filter out high quality studies and incorporate them in the existing text.

- To expand the topic to include a new question about once every 12-18 months.

If you would like to become a contributor for Clinical Evidence or require more information about what this involves please send your contact details and a copy of your CV, clearly stating the clinical area you are interested in, to Klara Brunnhuber (kbrunnhuber@ bmigroup.com).

\section{Call for peer reviewers}

Clinical Evidence also needs to recruit a number of new peer reviewers specifically with an interest in the clinical areas stated above, and also others related to general practice. Peer reviewers are healthcare professionals or epidemiologists with experience in evidence-based medicine. As a peer reviewer you would be asked for your views on the clinical relevance, validity, and accessibility of specific topics within the journal, and their usefulness to the intended audience (international generalists and healthcare professionals, possibly with limited statistical knowledge). Topics are usually 1500-3000 words in length and we would ask you to review between 2-5 topics per year. The peer review process takes place throughout the year, and our turnaround time for each review is ideally 10-14 days.

If you are interested in becoming a peer reviewer for Clinical Evidence, please complete the peer review questionnaire at www.clinicalevidence.com or contact Klara Brunnhuber (kbrunnhuber@bmigroup.com). 